\title{
O jogo como precursor de valores no contexto escolar
}

CDD. 20.ed. 796.05

\begin{tabular}{r|l} 
Silvio SENA* & $\begin{array}{l}\text { *Faculdade de } \\
\text { Ciências e Tennologia, } \\
\text { Universidade Estadual } \\
\text { Paulista - Presidente } \\
\text { Prudente. }\end{array}$
\end{tabular}

\section{Resumo}

Esta pesquisa estabeleceu como objetivo investigar o jogo como precursor na socialização de valores, no contexto escolar. Delimitou como objeto de análise a incorporação, pelas crianças, dos valores cooperação, solidariedade, respeito mútuo e perseverança. Nessa perspectiva, buscou-se fundamentação na Teoria Histórico-Cultural e em autores que advogam a educação numa perspectiva globalizadora. A metodologia, de predominância qualitativa, caracterizou-se como de intervenção, com medidas qualitativas e quantitativas, nas seguintes etapas: etapa diagnóstica; etapa de intervenção 1 ; e etapa de intervenção 2 . Nesse processo, o conhecimento produzido foi tratado como um fenômeno descritivo. A formalização dos diagnósticos, nas três etapas, deu-se por meio de observações participantes, registros escritos e intervenções do pesquisador em relação às crianças, por meio do jogo. Constata-se, como resultado, que houve uma sensivel diminuição na incidência de agressões físicas e verbais; notou-se um maior uso do diálogo, frente à necessidade da resolução de conflitos gerados nas situações lúdicas; percebeu-se um maior respeito às decisões coletivas; e observou-se que foram reduzidas as atitudes de discriminação e exclusão. Com base nos resultados do trabalho de campo e de seu arcabouço teórico, a pesquisa concluiu que o jogo é uma atividade de natureza social, portanto, torna-se fundamental compreendê-lo como componente de emergência e de enriquecimento da cultura lúdica; o professor de Educação Física deve ter um amplo e profundo conhecimento sobre o jogo e o desenvolvimento infantil; e, por fim, que o emprego do jogo, no contexto educacional, pode ser enriquecido e potencializado pela qualidade e frequência das intervenções do educador.

UniteRmos: Jogo; Valores; Crianças; Socialização.

\section{Introdução}

A pesquisa "O jogo como precursor de valores no contexto escolar" constitui-se como parte do projeto alternativo: "Desenvolvimento Psicomotor", estruturado na rede municipal de ensino de Presidente Prudente e voltado à minimização das dificuldades de aprendizagem de crianças, nas séries iniciais do Ensino Fundamental.

Julgamos necessário salientar que o motivo inicial que nos conduziu a esse trabalho foi a determinação, por parte da Administração da Secretaria Municipal de Educação de Presidente Prudente, de se implementar açôes direcionadas para o desenvolvimento psicomotor da criança. Essa indicação pautou-se nos resultados de uma avaliação psicomotora, aplicada às crianças das séries iniciais do Ensino Fundamental, a partir dos quais a rede municipal de ensino de Presidente Prudente elaborou a hipótese de que pelo menos parte das dificuldades de aprendizagem das crianças, no referido nível de ensino, teria sua gênese no insuficiente desenvolvimento psicomotor.

Por sermos, ao todo, três professores de Educação Física a integrar a rede municipal de ensino de Presidente Prudente, naquele momento, a Secretaria Municipal de Educação indicou três unidades de ensino (UE) para serem atendidas pelo projeto, dentre as quais a escola que abrigou esta pesquisa.

Tínhamos ciência de que um trabalho que pudesse vir a colaborar para o pleno desenvolvimento das crianças deveria atendê-las em seus anseios e necessidades. Ao se iniciar o projeto, tinha-se como meta a potencialização das capacidades motoras, 
afetivas, sociais e cognitivas das crianças, através de uma intervenção psicomotora, por meio do jogo.

Trabalhamos com os seguintes grupamentos: segundas séries - 10 crianças; terceiras séries - 12 crianças; e quartas séries - 11 crianças. Apesar de termos atuado com os três grupamentos, por escolha aleatória, o processo de análise desta investigação foi desenvolvido apenas em relação à turma de crianças das segundas séries. Tal opção pautou-se pelo fato de que, por não configurar como intenção desta pesquisa o caráter comparativo de uma turma em relação à outra, concluiu-se que tal decisão não implicaria um significativo prejuízo qualitativo, no que tange aos seus resultados. Desse modo, os sujeitos examinados foram as crianças, identificadas como: "C1"; "C2"; "C3"; "C4"; "C5"; "C6"; "C7"; "C8"; "C9" e "C10".

Tais crianças, oriundas das séries iniciais do Ensino Fundamental da unidade de ensino que acolheu a investigação, foram selecionadas pela equipe administrativo-pedagógica da UE, levando em conta os relatos e registros dos educadores, elaborados em reuniōes de Conselho de Classe, Ciclo e Termo. Vale dizer que o critério de que os professores fizeram uso, para a respectiva seleção, relacionava-se ao aspecto comportamental das crianças. Nos discursos proferidos pelos educadores, naquela ocasião, ficou evidenciado que as defasagens relacionadas à aprendizagem de conteúdos disciplinares específicos eram carreadas por atitudes e comportamentos inadequados das crianças, durante o desenvolvimento do processo ensinoaprendizagem. São exemplos as seguintes falas:

Aquela criança não quer saber de nada, nem se dispõe a tentar;

Não estou aguentando mais, quando tento fazer uso da palavra para explicar algum conteúdo, ele teima em falar ao mesmo tempo em que eu; No intervalo, na sala de aula e nos momentos da Educação Física, não tem jeito, ele agride os companheiros a todo o momento.

Ao nos beneficiarmos dos primeiros contatos com as crianças, pudemos perceber que a maioria delas demonstrava, no aspecto motor, um padrão satisfatório em relação às habilidades de locomoção, estabilização e manipulação. Tal conclusão pautou-se na observação das crianças nas aulas, pois ficou constatado, nos jogos propostos, que a maior parte das crianças dominava de modo satisfatório, as habilidades locomotoras, manipulativas e de estabilização, empregando-as para a superação dos desafios ali propostos.

Isso significa dizer que o motivo dessas dificuldades não seria unideterminado por uma defasagem de ordem psicomotora, mas se centraria em múltiplas causas, como, por exemplo, a ausência de práticas adequadas que pudessem vir ao encontro dos anseios e necessidades infantis. Desse modo, acarretaria a necessidade de dar uma ênfase maior aos conteúdos, às motivações, aos valores e aos princípios que poderiam se transformar na condição prévia para a mobilização das crianças rumo à conquista de novos e mais evoluídos patamares de saberes e de habilidades.

Com base nas atitudes que permearam aquele contexto, concluímos, em consonância com o ponto de vista das professoras regulares, que se fazia necessário um tratamento especial aos conteúdos atitudinais, porque, se o diálogo, o respeito mútuo, a solidariedade etc., não fizessem parte das inter-relações, naquele momento, a promoção do ensino - e, por consequência, também da aprendizagem - seria tarefa árdua e de difícil alcance.

Nesse sentido, em face dos elementos expostos, elegemos, predominantemente, os conteúdos atitudinais como finalidade central a ser contemplada, no trabalho, e que se tornou também objeto de estudo desta pesquisa. Ressaltamos que compreendemos que o tratamento dado aos conteúdos conceituais, procedimentais e atitudinais ocorre de forma integrada e que foi apenas em razão do recorte necessário que enfatizamos uma das dimensões, sem, todavia, desconsiderar as outras.

Nesse enfoque, outorgou-se a formação de valores como questão norteadora desta pesquisa. Consideramos, também, que a pesquisa teria maior alcance, se viesse a se desenvolver por meio de procedimentos de intervenção durante o trâmite processual do jogo, como prática pedagógica. Nessa perspectiva, estabelecemos o jogo como objeto de análise e principal instrumento, isto é, objetivamos, por meio dele como foco central desta investigação, a socialização e suposta incorporação, pelas crianças, de comportamentos que justificariam as inter-relaçōes, respaldadas nas seguintes categorias:

- Respeito mútuo: pretendíamos avaliar se o aluno se inter-relacionaria com os outros, em situações lúdicas, respeitando as combinaçôes coletivas (regras), pontos de vista de todos e resolvendo os conflitos através de diálogo. Nesse entendimento, frente aos embates e situaçōes conflituosas geradas nas inter-relações, através do jogo, elegemos como cerne de nossa observação, durante as etapas nas quais se desenvolveu a empíria, o fato de a criança ter avançado, ou não, no domínio de sua vontade de agredir ou de discriminar os companheiros, de 
modo a fazer valer o uso do diálogo e da reciprocidade, voltados à contemplação dos direitos e deveres de todos os protagonistas daquela realidade. Em suma, essa categoria se dirigiu de maneira direta às manifestações de agressividade, no ambiente educacional. $\mathrm{Na}$ concepção adotada, agressividade não se refere apenas às agressões físicas ou verbais, mas também às atitudes hostis, ligadas ao descaso, ao desprezo, à usurpação de direitos e todo e qualquer tipo de discriminação com relação ao outro.

- Cooperação: buscávamos avaliar se o aluno participaria de atividades corporais, adotando uma postura colaborativa, ou seja, se ouvia e respeitava os pontos de vista do outro, trocava ideias, experiências e aproveitava críticas e sugestôes, para superar desafios comuns em parceria. Em outras palavras, essa categoria não limitou sua caracterização, apenas, à capacidade da criança em operar com o outro. O foco de análise considerou, igualmente, atitudes que se respaldaram na colaboração incondicional da criança, no que concerniu à contemplação dos objetivos e metas propostos no âmbito coletivo. Nesse entender, a criança que se encontra em um nível de desenvolvimento plenamente satisfatório ouve e leva em conta pontos de vista, experiências e tira proveito de críticas, apontamentos e sugestóes do outro, para superar desafios comuns em parceria.

- Solidariedade: pretendíamos avaliar se o aluno adotaria atitudes de ajuda mútua, quer dizer, se auxiliaria os que apresentassem maiores dificuldades e se aceitaria ajuda dos mais competentes, em um ambiente onde prevalecessem o respeito, o incentivo, a motivação e o carinho pelo outro. Dito de outro modo, se a criança se comprouve e se propôs amparar e ajudar seus iguais, em razão de seus fracassos e/ou dificuldades, bem como se esteve receptiva às tentativas de atenção, carinho e ajuda provenientes deles, diante das dificuldades vivenciadas por ela.

- Perseverança: buscávamos avaliar se o aluno demonstraria segurança para experimentar, tentar e arriscar, sem desistir, em situaçōes cotidianas da aprendizagem da cultura corporal. Nessa perspectiva, o foco de análise considerou como ponto central, nesta investigação, o comportamento da criança perante suas dificuldades e as de seus coetâneos, ocorrido durante os momentos em que aquele ambiente esteve permeado pelo jogo. Em outras palavras, se a criança se propôs tentar superar os desafios individuais e coletivos que emergiram através do jogo, naquela realidade.

Vale dizer que o jogo, por ser um elemento da cultura corporal, integra o bloco de conteúdos da
Educação Física. Segundo os Parâmetros Curriculares Nacionais (PCNs), é um tipo de conteúdo pertinente para as séries iniciais do Ensino Fundamental, pois pode ter

[...] uma flexibilidade maior nas regulamentaçōes, que são adaptadas em função das condições de espaço e material disponíveis, do numero de participantes, entre outros. São exercidos com um caráter competitivo, cooperativo ou recreativo em situaçôes festivas, comemorativas, de confraternização ou ainda no cotidiano, como simples passatempo e diversão (BRASIL, 2001, p.49).

O jogo, no enfoque desta pesquisa, é visto como uma atividade que tem características próprias e cujo conteúdo pode colaborar para o pleno desenvolvimento das capacidades motrizes e expressivas da criança, além de representar um meio para se socializarem os demais conteúdos curriculares desse nível de ensino, com destaque para a formação de valores.

Para as séries iniciais do Ensino Fundamental, defendemos uma concepção de educação com vista a superar o conceito clássico, baseado apenas em modelos conceituais, que impera nas instituiçóes educacionais. "Os conceitos se referem ao conjunto de fatos, objetos ou símbolos que têm características comuns [...]. São exemplos de conceitos: mamífero, densidade, impressionismo, função, sujeito, romantismo, demografia, nepotismo, cidade, potência, concerto, cambalhota, etc." (ZaBALA, 1998, p.42).

Essa proposta aponta para a necessidade de se ampliar a prática educativa dos agentes sociais (professor e aluno) para outros campos, como os procedimentos, que, segundo ZabalA (1998, p.43), se consubstanciam em "um conjunto de ações ordenadas e com um fim, quer dizer, dirigidas para a realização de um objetivo". E, principalmente, as atitudes, de maneira a considerá-las como significantes potencializadores das capacidades humanas. Os conteúdos atitudinais podem ser agrupados em valores, atitudes e normas.

[...] entendemos por valores os princípios ou as idéias éticas que permitem às pessoas emitir um juízo sobre as condutas e seu sentido; as atitudes são tendências ou predisposições relativamente estáveis das pessoas para atuar de certa maneira, ou seja, é a forma como cada pessoa realiza sua conduta de acordo com valores determinados; por sua vez, as normas são padrões ou regras de comportamento que devemos seguir, em determinadas situaçôes, que 
obrigam a todos os membros de um grupo social (ZaBAla, 1998, p.46-7).

$\mathrm{O}$ atual sistema de ensino, no Brasil, cumpre e legitima uma educação de caráter disciplinar e propedêutico. Em outras palavras, a realidade nos faz deparar com um ensino focado no percurso rumo à universidade pelos mais competentes e com uma prática docente limitada aos conteúdos fragmentados de cada disciplina da grade curricular

O resultado desse processo é uma seleção, uma organização dos conteúdos de aprendizagem a partir de critérios disciplinares. [...]. Seleção que, na maioria dos planos de estudos oficiais do mundo, concretiza-se em um conjunto de disciplinas isoladas em que se dá uma maior ou menor ênfase a umas sobre as outras, nas quais a estrutura interna de cada uma delas sempre segue a lógica disciplinar. (ZABALA, 2002, p.18).

Para a melhoria da qualidade do ensino, propomos como estratégia uma educação mais equilibrada. Há, nas instituições escolares de Ensino Fundamental, ênfase no domínio conceitual. Esses conteúdos deveriam ter uma leve prevalência sobre os demais somente no Ensino Médio, período em que a base da personalidade do educando já se encontra estruturada, e o nível de sua capacidade de abstração já tende a apresentar tal complexidade que lhe permite a aquisição de conhecimentos, através da predominância de relações estabelecidas nessa dimensão do ensino. Todavia, a realidade nos apresenta a secundarização do domínio procedimental e, principalmente, do atitudinal, nesses níveis de ensino.

Por sua vez, a Educação Física é contemplada pelo saber fazer de grande parte de seus profissionais, regido por práticas mecânicas, estereotipadas e limitadas à padronização de comportamentos. Tal realidade reflete, mesmo que por meio de ato inconsciente desse professor, em uma contribuição positiva ou negativa na formação da personalidade da criança. "Qualquer proposta direcionada a conseguir que alguém aprenda está condicionada ou determinada por uma ideia, consciente ou inconsciente, de pessoa e de sociedade" (Zabala, 2002, p.43-4).

Para que se torne possível uma definição de cidadão e, por conseguinte, de sociedade que se pretende formar, faz-se imperiosa a necessidade da revisão dos critérios a serem fixados, no processo de seleção dos conteúdos e do trato desses conteúdos por esta ou aquela disciplina. A forma disciplinar da composição dos conteúdos de aprendizagem, no atual sistema educacional brasileiro, que entende o ser humano fragmentado, obstaculiza a estruturação de uma prática docente comprometida com a formação global da criança. Assim, o ato educativo deve fazer convergir os objetivos funcionais das disciplinas às finalidades que a educação tem por atribuição atender.

As práticas têm objetivos para os quais se dirigem os participantes com sua ação combinada, e uma finalidade que se refere aos valores implícitos e explícitos que a prática manifesta durante o processo de sua realização (Puig, 2004, p.74, grifo nosso).

É patente o fato de que toda atividade educativa carrega em seu cerne um perfil mais ou menos concreto de cidadão que pretende formar, isto é, princípios, valores, crenças e pautas de comportamento que refletem uma determinada concepção de sociedade. Essa correlação não existe somente quando as açóes de ensino são focadas em âmbitos explicitamente pessoais ou sociais. Pode ocorrer em situaçôes de ensino-aprendizagem de conteúdos aparentemente neutros, como no estudo de fenômenos advindos da química, das fórmulas matemáticas, entre outras. Por meio das inter-relaçóes professor-alunos e alunosalunos, estabelecidas na prática educativa, é atribuída certa importância, no que se refere às imagens e modelos previamente definidos de pessoa e de sociedade que se acredita ser necessário formar. A qualidade das inter-relaçóes e as regras fixadas definem a natureza do processo ensino-aprendizagem, explicitada e reiterada no desenvolvimento do ato educativo. Tal prática pode otimizar no educando capacidades de participar, de interagir, de agir de maneira autônoma, de cooperar, de perseverar, de respeitar o outro - ou de discriminar, de agredir, de não cooperar, ou seja, pode conduzi-lo à exacerbação da competição e ao individualismo.

Até o momento, as capacidades humanas que o sistema educativo tem priorizado como importantes são as competências cognitivas - mas nem todas, apenas aquelas consideradas mais relevantes, relacionadas às disciplinas ou matérias tradicionais. Contudo, os discursos que predominam nas instituiçôes educacionais são os que advogam a pertinência e a necessidade de o ensino formal desenvolver, também, as demais capacidades humanas, que são "[...] capacidades cognitivas ou intelectuais, motoras, de equilíbrio e autonomia pessoal (afetivas), de relação interpessoal e de inserção e atuação social" (ZABALA, 1998, p.28). Esse - por enquanto - utópico objetivo da educação permeia os projetos político-pedagógicos das unidades de ensino, os planos anuais de trabalho do professorado, os sistemas de avaliação, etc. 
$\mathrm{Na}$ prática educativa, os conteúdos conceituais, procedimentais e atitudinais são indissociáveis; no entanto, para uma melhor compreensão de como se dá, em seu todo, o desenvolvimento infantil, estes foram assim categorizados. Nesse entendimento, de forma inter-relacionada, tais conteúdos são mobilizados numa mesma esfera de relações, isto é, o jogo como elemento e produto da cultura, que favorece as inter-relaçōes, é, por si só, um agente que pode contribuir para a contemplação da globalidade do

\section{Métodos}

A investigação, realizada em 10 meses, foi estruturada nas seguintes etapas: a etapa diagnóstica esteve constituída de 13 atividades; a etapa de intervenção 1 contou com 16 atividades; e a etapa de intervenção 2, por sua vez, registrou 23 atividades. Nas três fases da pesquisa, o jogo se configurou em uma ampla gama de atividades locomotoras, manipulativas e de estabilização, envolvendo ou não materiais, como: tipos diversos de bolas, bambolês, giz, elásticos, petecas, cones, trampolim de ginástica, "plinton" (base de apoio para atividades de agilidade), etc. Tais práticas foram planejadas, organizadas, sistematizadas e eleitas a partir de propostas, sugestóes e preferências da maior parte dos protagonistas (professor e alunos) daquela realidade. Como exemplos, citamos os diversos tipos de pega-pega, de pré-desportivos, de brincadeiras tradicionais, de cantigas de roda, de atividades de agilidade envolvendo aparelhos ginásticos, entre outras.

As crianças permaneceram na UE por um tempo médio de oito horas diárias, participando de atividades variadas. Naquele momento, a UE oferecia o ensino oficial para as terceiras e quartas séries, no período matutino, e para as segundas séries, no período vespertino. Desse modo, pela necessidade de o projeto ser realizado em período contrário ao da grade curricular, a turma das segundas séries foi atendida no período matutino.

No princípio deste trabalho, precisávamos de um instrumento que nos oportunizasse o acesso ao nível de desenvolvimento, referente às categorias de análise, em que se encontravam as crianças. Em outras palavras, teríamos que realizar uma sondagem (avaliação) que nos possibilitasse, com fidedignidade, o acesso ao conhecimento relativo ao nível de desenvolvimento atitudinal das crianças, quer dizer, a uma organização e sistematização do jogo como instrumento de intervenção na formação de valores. Nesse sentido, em média, nas 12 desenvolvimento da criança. Em decorrência, nesta pesquisa, o jogo é considerado como um rico instrumento de intervenção da Educação Física, o qual deve ser organizado e sistematizado através de regras que garantam princípios, normas e valores voltados para as necessidades de um pleno e positivo desenvolvimento da personalidade da criança. Em outras palavras, a intervenção do educador deve convergir para uma formação da criança nos aspectos pessoal, interpessoal e social.

últimas aulas de cada etapa, formalizamos os diagnósticos do desenvolvimento individual das crianças, por meio do jogo. Nessa acepção, o trabalho tomou como eixo norteador as implicações que o jogo representou no tocante ao aspecto comportamental das crianças, ao longo das três etapas da investigação e relativas às categorias elencadas.

Dessa maneira, a interpretação dos dados foi efetivada com base no amplo arcabouço teórico oferecido pelos autores da Teoria Histórico-Cultural, com destaque para VyGOTSKY $(1989,1991)$, LEONTIEV (1988), Elkonin (1998), Pontecorvo (2005), Puig (2004). Mukhina (1995) e Lima (2003), além da contribuição de estudiosos que advogam a educação numa perspectiva globalizadora, de que são exemplos Zabala $(1998,2002)$, Garófano (2005) e SanMartín (2005), entre outros.

$\mathrm{Na}$ vertente Histórico-Cultural, o desenvolvimento do sujeito e da espécie humana é o resultado de um processo sócio-histórico. Nessa acepção, uma coletividade se constitui a partir de pessoas com singularidades próprias, ou seja, as origens da vida consciente e do pensamento abstrato da criança devem ser investigadas na interação com as condições de existência e nas formas histórico-sociais com as quais ela se deparou. Nesse processo, indivíduo e meio se afetam de modo recíproco e dialético.

Por sua vez, ZABALA (2002) define a Perspectiva Globalizadora do ensino apoiado em três princípios, a seguir: a) $O$ objeto do ensino é a realidade: a necessidade de compreender a realidade para intervir nela e transformá-la; b) A realidade, sua compreensão $e$ atuação são complexas: a constatação de tal complexidade impele a escola a acolher por obrigação básica a função de formar o aluno, para que seja capaz de dar resposta de sua própria condição complexa; c) Apesar de suas deficiências, 
as disciplinas são os principais instrumentos para $o$ conhecimento da realidade: dada a dispersão $\mathrm{e}$ fragmentação do saber, a maioria dos conhecimentos disciplinares é insuficiente para apreender em todas as suas dimensóes o conhecimento da realidade; apesar desses limites, tais conhecimentos são os únicos instrumentos rigorosos de que dispomos.

No recorte desta pesquisa, ELKONIM (1998), na ótica da teoria Histórico-Cultural, concebe o jogo como espaço privilegiado para a criança se apropriar dos sentidos que circulam em sua cultura, de forma a assimilá-los e nela viver. Na Perspectiva Globalizadora, o jogo “[...] inter-relaciona conteúdos de Educação Física com outras áreas e eixos transversais. Sua prática potencializa atitudes e hábitos de tipo cooperativo e social baseados na solidariedade, na tolerância, no respeito e na aceitação das normas de convivência" (Valenzuela, 2005, p.91). Em síntese, como ponto de convergência, conclui-se que ambas as vertentes preconizam o jogo como um instrumento do qual a criança faz uso para, progressivamente, projetar-se, entender, atuar e intervir nos cenários político, social, cultural e estético do mundo objetivo do qual faz parte.

Nessa perspectiva, a investigação, de predominância qualitativa, se caracterizou como de intervenção, na qual o jogo atuou como o principal instrumento. Vale dizer que a pesquisa de intervenção faz a mediação entre a teoria e a prática, a partir do momento explícito, justificado e delimitado em que problematiza a realidade e propõe alternativas de ação, pautadas no conhecimento teórico e na interação social.

Desse modo, o estudo elaborado foi retratado através de um processo que apontou ideias relevantes, selecionadas e vivenciadas, num contexto que concebeu o jogo como um recurso precursor de socialização.

Os diagnósticos foram concluídos, utilizandose os seguintes instrumentos: observação participante, registros escritos e intervençôes do "pesquisador" em relação ao público-alvo, inseridos em contexto coletivo no ambiente escolar, por meio do jogo amparado por regras de natureza interativa, solidária, cooperativa, respaldadas em reciprocidade e trocas de pontos de vista. Salientamos, ainda, que a mensuração desta pesquisa foi estruturada por meio de variáveis nominais.

Nos primeiros contatos com as crianças, foram expostos e discutidos os motivos que conduziram a UE a introduzir esse projeto de ensino. Segundo tal propositura, as regras e princípios que nortearam as inter-relações, naquele contexto, foram previamente debatidos, argumentados, combinados e convencionados por todos os envolvidos, por meio de um processo voltado para o estabelecimento de normas consensuais.

A sondagem diagnóstica e todo o percurso subsequente do trabalho foram estruturados de maneira a priorizar a composição das regras, abaixo citadas. Tais regras, eleitas pela decisão da maior parte dos protagonistas (professor e alunos) daquele contexto, foram pautadas em relaçóes positivas, com base nos referenciais que definiram e delimitaram as categorias de análise desta pesquisa. As regras foram as seguintes: 1) cada turma teria direito a uma média de três horas-aula semanais, em que cada aula seria composta por um tempo de 90 minutos; 2) as aulas deveriam ter, em sua estrutura, três momentos - o momento das combinações: espaço temporal reservado para se combinar as atividades a serem desenvolvidas no dia; momento da atividade coletiva: caracterizavase na prática instituída e desenvolvida através da participação ativa de todas as crianças, e; se fizessem por merecer, o momento espontâneo: que se resumia naquele em que cada criança poderia vir a participar da atividade de sua preferência; 3) todas as aulas deveriam ser apresentadas em forma de propostas passíveis de mudança, desde que a possibilidade de alteração, ou mesmo de substituição das atividades, fosse uma decisão coletiva, aprovada pela maior parte dos indivíduos que constituíam aquele grupo; 4) não seriam toleradas atitudes de agressividade para com nenhum dos integrantes do grupo, tanto no plano verbal como no físico. No caso de agressão verbal, se seguida de arrependimento e pedido de desculpas do agressor e aceitação dessa desculpa pela criança agredida e pelas demais do grupo, a criança poderia vir, de novo, a participar da atividade coletiva, bem como a usufruir o direito ao momento espontâneo. Entretanto, no caso de agressão física, a criança teria o direito de participar da atividade coletiva, porém, seria privada de participar do momento espontâneo da aula em questão; 5) as crianças poderiam, em cada aula, usufruir do direito de jogar a atividade de sua preferência (momento espontâneo), desde que, num primeiro momento, viessem a colaborar de todas as formas (cooperando, respeitando, solidarizando-se e perseverando), nos momentos das combinações e do desenvolvimento da atividade coletiva; 6) o preconceito e a discriminação de cor, de classe, de gênero, por afinidade ou competência, seriam considerados, pelo grupo, como faltas graves e tomados como agressão verbal, motivo pelo qual foram tratados e ponderados segundo os ditames estabelecidos na regra de $n^{\circ} 4$. 
Ao transgredir uma regra, a criança não foi penalizada de modo literal. Temos ciência de que tratar com equidade todos os sujeitos de certa comunidade significa respeito às singularidades, ou seja, à maneira particular de pensar, às características positivas e negativas da personalidade de cada indivíduo e, principalmente, aos motivos que o induziram a transgredir ou não as regras, instituídas numa determinada comunidade social. Foi nessa perspectiva que, após atividades coletivas nas quais a todos e sem reservas foi dado o direito de participar, as ocorrências e transgressões foram debatidas e avaliadas por todos os elementos que formavam aquele grupo, por meio de assembleias. Nas aulas em que ocorreram casos de transgressōes às regras, com exceção de agressões no plano físico, coube ao transgressor o direito de fazer sua defesa, através da exposição oral de seus motivos, considerações e, se fosse o caso, da efetivação do pedido de desculpas. Ao final dessa etapa, o grupo decidia se a criança em questão teria ou não o direito a participar do momento espontâneo. É de suma importância se frisar que, por meio dessas assembleias, as crianças decidiam a pertinência, coerência e viabilidade das regras supracitadas, de sorte a apontar e sugerir, caso se fizesse necessário, a alteração ou, até mesmo, a eliminação de alguma delas.

Com esse procedimento de tomada de consciência de um âmbito normativo que tinha se tornado conflitivo, consegue-se, por um lado, melhorar as condutas impróprias, e, por outro, mostrar que as normas são produtos que podem ser discutidos e mudados (Puig, 2004, p.179).

Pelo fato de o número de crianças da turma das segundas séries (sujeitos) totalizar apenas 10 indivíduos, o critério de observação e aferição dos registros foi o de contemplarmos todos os indivíduos, em todas as aulas desenvolvidas, ao longo das etapas que estruturam e sistematizaram a pesquisa. Todavia, com uma ênfase maior às ocorrências que viessem a se destacar.

Os registros foram estruturados imediatamente após cada aula. Nesse espaço temporal, tivemos 45 minutos exclusivos para esse fim. Sabíamos que a situação ideal seria termos um profissional auxiliar para observar e praticar o ato do registro, no exato momento das ocorrências, de modo a se fazer valer o potencial afetivo incluso no contexto de cada situação, ocorrida através do jogo enquanto fenômeno social. Todavia, a realidade daquele momento não nos contemplou com essa significativa possibilidade de trabalho.

Os indicadores usados para determinar o desenvolvimento da criança, em cada uma das etapas, pautaram-se nos referenciais que caracterizaram e definiram cada categoria, utilizados para se efetivar a análise. De acordo com seu processo individual de desenvolvimento, a criança teve seu desenvolvimento enquadrado, em cada uma das etapas, nas respectivas categorias: $P S$ (plenamente satisfatório), $S$ (satisfatório), ou NS (não satisfatório).

A participação da criança foi considerada como $P S$, quando apresentou predominância de comportamentos que vieram ao encontro dos indicadores que caracterizam e definem a categoria em análise; foi enquadrada como $S$, quando a maior parte de suas atitudes mesclou comportamentos dúbios acordo x desacordo - para com os indicadores da categoria em questão; e $N S$, quando a maior parte das atitudes da criança demonstrou pouca harmonia para com os referenciais que definem e caracterizam a categoria analisada. Nesse sentido, tendo em vista as diversidades exibidas naquele contexto, mesmo que numa perspectiva voltada à coletivização, o desenvolvimento de cada criança foi considerado como um processo único e singular.

Nesse enfoque, não tivemos por intenção fazer uma apologia do jogo como a panaceia da Educação Física para os problemas comportamentais das crianças, nas séries iniciais do Ensino Fundamental. No entanto, ele foi tomado como um agente que pode vir a colaborar na contemplação do propósito maior que permeia os discursos de políticos, pais e educadores, no atual cenário político e social em que nos encontramos, ou seja, o desenvolvimento global de nossas crianças.

Assim, já na etapa diagnóstica, durante um interstício médio de 12 horas-aula, formalizamos os diagnósticos individuais, através do jogo, considerando a capacidade do educando em socializar atitudes regidas pelas categorias respeito mútuo, cooperação, solidariedade e perseverança.

Os diagnósticos individuais dos níveis de desenvolvimento das crianças, em relação às categorias em destaque, nessa etapa, permitiram o acompanhamento, ao longo do ano letivo, dos avanços pessoais de desenvolvimento, de maneira a se considerar as particularidades de cada indivíduo, perante as múltiplas situações de socialização, ocorridas naquele contexto.

$\mathrm{Na}$ etapa de intervenção 1 , num primeiro momento, com base no diagnóstico anterior, elaboramos e desenvolvemos atividades centradas na consideração do jogo, no contexto escolar, como instrumento precursor na socialização das categorias elencadas por esta pesquisa. Como segundo momento dessa etapa, desenvolvemos nova sondagem, ao final 
do primeiro semestre, usando os mesmos instrumentos e procedimentos empregados na etapa diagnóstica, de sorte a podermos comparar e identificar, durante o interstício observado, os avanços individuais. Estabelecemos como finalidade, igualmente, detectar os possíveis equívocos, o que foi considerado necessário para realizarmos acertos, alterações e re-delineamento da pesquisa, de acordo com os objetivos propostos.

$\mathrm{Na}$ etapa de intervenção 2 , também no primeiro momento, levamos em conta os avanços e dificuldades individuais constatados na sondagem de encerramento

\section{Resultados e discussão}

Para que possamos ilustrar os avanços e percalços da pesquisa, em sua integralidade, resta-nos, ainda, expor ao leitor o trâmite processual no qual se deram as implicações das atitudes individuais, num cenário mais amplo, isto é, no das inter-relações em contexto grupal.

Nessa perspectiva, pretendemos apresentar a forma de análise e destacar o desenvolvimento de todas as crianças da turma das segundas séries, ao longo das etapas que estruturaram e deram forma a este trabalho. Para tanto, empregaremos três aulas como amostragem, cada qual referente a uma unidade/aula de cada etapa que compôs esta pesquisa. Como cerne de nossa objetivação, intencionamos, através do jogo representado pelas atividades descritas, a seguir, ilustrar os processos de desenvolvimento pessoal e a influência e implicações destes no âmbito dos conteúdos atitudinais, naquele coletivo.

\section{Etapa diagnóstica}

$\mathrm{Na}$ etapa diagnóstica, tomamos como exemplo as atividades $\mathrm{n}^{\circ} 1$ e $\mathrm{n}^{\circ} 2$, intituladas respectivamente: Será que eu consigo? Eh, eu sei quicar!

Julgamos relevante salientar que, apesar de as atividades desta etapa se consubstanciarem em performances individuais, nelas observamos a instalação de atitudes referentes às categorias de análise eleitas por esta investigação.

O respeito mútuo foi verificado na simples concessão ou não ao outro do direito à palavra e a atuar conforme o combinado; se, ao fracassar, mesmo assim foi respeitado nas suas possibilidades e limitaçōes; se foi considerado em sua opinião e se, ao discordarem dele, lhe foi garantido o uso do do primeiro semestre, para reestruturarmos as atividades e estratégias centradas no jogo como instrumento de intervenção na socialização de valores, para o segundo semestre, caso se fizesse necessário. Ao término do segundo semestre, como segundo momento dessa etapa, realizamos, por meio dos mesmos instrumentos usados até aquele momento, a sondagem final da pesquisa. Da mesma forma que nas anteriores, o objetivo foi o de detectarmos, da maneira mais fidedigna possível, os avanços nos processos individuais de desenvolvimento nas categorias desta pesquisa e os seus reflexos, no âmbito coletivo.

diálogo como instrumento mediador na resolução de problemas e conflitos interpessoais. Observouse a cooperação, na capacidade da criança em submeter-se às regras, isto é, na sua capacidade de esperar com paciência o seu momento de atuar e se, ao atuar, respeitou as zonas limítrofes estabelecidas pelas normas, ali instituídas. São exemplos: "se a criança se posiciona na coluna e espera pacientemente a sua vez"; "se não rechaça e rotula o outro, perante situaçóes de fracassos dos companheiros"; "se procura, de forma fiel, respeitar as regras instituídas". A solidariedade foi constatada nas atitudes em que, diante das dificuldades dos companheiros e das suas próprias, se a criança demonstrou disposição e prazer em auxiliar e, caso se fizesse necessário, em ser auxiliada. Exemplo: "se motiva os companheiros e permite ser motivado por eles nas dificuldades em executar, entre outros, 'a parada três apoios', 'o rolamento', 'os saltos', e "se apóia o outro e lhe aponta possibilidades de ação voltadas à superação dos desafios que se apresentarem". Notou-se a perseverança, no grau de persistência da criança no que tangeu a praticar quantas tentativas fossem necessárias para obter a contemplação de seu objetivo. Nesse caso, por exemplo: "executar a parada três apoios", "conseguir praticar o rolamento", "conseguir correr, saltar no trampolim e aterrissar no colchão no local determinado".

Ao se desenvolverem as atividades, num primeiro momento, apresentamos os materiais que deveriam ser usados naquela aula: colchão, trampolim de ginástica e três gavetas de "plinton". Na sequência, instigamos as crianças para que fornecessem sugestôes de possibilidades de uso dos supostos materiais. As 
crianças "C3", "C10", "C7" e "C9" demonstraram, nesse momento da aula, comportamentos que em muito dificultaram o seu desenvolvimento: não souberam ouvir e esperar com paciência a sua vez, para fazerem uso da palavra, levantaram-se e provocaram de forma frequente e intensa as demais crianças. "C3" provocou, em especial, seus parentes " $\mathrm{C} 1$ " e "C2". Por seu turno, tais crianças, sendo provocadas, manifestaram atitudes de enfrentamento perante ele, através de agressóes físicas e verbais. "C7", "C10" e "C9", além de provocarem e agredirem de maneira gratuita as demais crianças, tanto no plano verbal como no físico, exigiram que a atividade coletiva fosse o "futebol". Por sua vez, ao serem agredidos por "C7" e "C10", "C6" e "C8" recusaram-se a participar das atividades coletivas. Tais ocorrências vieram a gerar situaçōes de forte turbulência, naquela realidade.

"C4" cobrou a colaboração das demais crianças e apontou, de maneira lógica, a maioria das possibilidades de utilização do material apresentado. $\mathrm{Da}$ mesma maneira, a criança "C5", como a última, deu sugestôes de atividades para com os materiais e solicitou a colaboração das demais. "C4" enfatizou aos companheiros que o tempo ali, mal utilizado, faria falta no momento espontâneo. Todavia, percebeu-se um elevado grau de concorrência pela liderança entre essas duas crianças, o que culminou em frequentes situaçõos de estresse e desentendimentos entre ambas, refletindo de modo negativo nas inter-relações daquele contexto.

Como segundo passo daquela aula, correspondendo ao momento da atividade coletiva, através da intervenção do professor, o grupo estruturou duas atividades. Na primeira, deveriam realizar a parada três apoios no colchão e, na sequência, praticar o rolamento (cambalhota). Na segunda, deveriam correr e, com a utilização do trampolim, saltar por sobre as três gavetas sobrepostas de "plinton", de sorte a aterrissar no colchão posicionado imediatamente após as gavetas. A distância entre o colchão e as supostas gavetas seria progressivamente ampliada, à medida que todos efetivassem a tentativa de saltar a distância do momento, com sucesso ou não. Quando não houvesse nenhuma criança mais a superar a sucessiva complexidade dos desafios, a distância entre o colchão e o "plinton" não seria mais ampliada.

$\mathrm{Na}$ primeira atividade, combinou-se que as tentativas deveriam ser realizadas respeitando-se a ordem de um posicionamento das crianças, em coluna. A criança teria direito a três tentativas, em cada momento em que atuasse, sendo bem sucedidas ou não. Após a realização das tentativas, a criança deveria retornar ao final da coluna e aguardar até que todas as outras pudessem vir a usufruir do mesmo direito, a fim de que, de novo, ao chegar sua vez, pudesse realizar mais três tentativas. É importante salientar que "C5" apresentou atitudes de solidariedade para com as dificuldades de seus companheiros, auxiliando-os, de modo a apresentar sugestōes de possibilidades de ação na busca pela superação das dificuldades verificadas. As crianças "C3", "C7", "C10" e "C9" não se portaram segundo a organização dos princípios e regras instituídos. No momento em que cada um atuou, após fazerem uso das três tentativas a que tinham direito, manifestaram as seguintes falas: "deixa eu tentar mais uma vez?”; "eu não vou sair daqui!"; "ninguém vai me impedir de brincar do jeito que eu quero"; "quem vai me tirar daqui?". Como consequência dessas atitudes, em que, inclusive, o professor foi desafiado, as demais crianças, inconformadas com a situação e lideradas por "C4" e "C5", entraram em embate com elas, de forma a agredi-las nos planos físico e verbal.

O sujeito pesquisador, em convergência para com os elementos que caracterizam e amparam uma pesquisa de intervenção e por entender que a mera compreensão das normas ou o simples domínio da capacidade de julgamento moral da criança não assegurariam um comportamento correlato às regras, veio a intervir. A intervenção nessa atividade, como nas demais que compuseram este trabalho, ocorreu no sentido de abrandar os ânimos, ouvir, confrontar e discutir os pontos de vista, resgatar os combinados, solicitar que as crianças envolvidas se retratassem e, na sequência, se possível, dar continuidade às ações em curso. É na rotina desse processo que os valores são interiorizados, ou seja, na multiplicidade e reiteração de ocorrências em que há a quebra e o restabelecimento das regras.

Boa parte do problema implícito na transição do julgamento para a ação reside na capacidade de adquirir hábitos que garantam a ação que efetivamente se quer realizar. Mas a aquisição de hábitos depende da repetição, da possibilidade de realizar mais vezes os mesmos comportamentos pautados. A redundância aqui predispõe à virtude (PUIG, 2004, p.64).

Voltando à descrição daquela aula, na segunda atividade, os comportamentos e os seus reflexos se repetiram, isto é, como na anterior, houve situações de conflitos, que vieram a gerar atitudes hostis do mesmo tipo e nível das ocorridas na primeira atividade.

É relevante enfatizar que as crianças "C10" e "C9", apesar de terem socializado comportamentos impróprios, pareceram, na maior parte das situaçôes, 
crianças carinhosas e dispostas a auxiliar os companheiros, em suas dificuldades. Tanto na primeira como na segunda atividade, estiveram, por meio de elogios e incentivos, a apoiar os companheiros, bem como a lhes fornecer sugestôes de possibilidades de ação, frente aos desafios propostos. Contudo, várias outras crianças mostraram comportamentos contrários a esses, com destaque para "C1", "C3", "C7" e "C6".

Pelas qualidades demonstradas, percebemos que "C2" era querido e bem aceito pelas demais crianças. Por sua vez, mesmo exibindo atitudes de solicitude e companheirismo para com alguns coetâneos, em razão das múltiplas situações de violência originadas por ele, "C9" não comungava da mesma aceitação.

Nessa aula, todas as crianças foram privadas do momento espontâneo, oito das quais por terem se agredido no plano físico e duas ("C6" e "C8") por terem se negado a participar no momento do desenvolvimento das atividades coletivas. Um ponto importante a se destacar é que, até aquele momento, não havia ainda se constatado a interação entre "C6", "C8" e as demais crianças.

"C4" e "C5", inconformadas com as consequências de suas atitudes, questionaram a sanção, argumentando a primeira: "não é justo, professor, nós só tentamos fazer com que a aula desse certo, não temos culpa"; a segunda: "é, professor, a culpa não é nossa e sim desses meninos, eles só sabem brigar e não respeitar o que a gente combina junto". As demais crianças, por meio de sucessivos pedidos, reclamaram suas absolvições da sanção, através das falas a seguir: "ô, professor, deixa a gente brincar, vai", "eu não vou mais bater em ninguém, eu prometo, mas, por favor, me deixa brincar?", "se o senhor não me deixar brincar, eu não vou mais vir pra esse projeto".

\section{Etapa de intervenção 1}

$\mathrm{Na}$ etapa de intervenção 1, analisaremos o futebol como atividade coletiva. Essa atividade, como as demais ocorridas em outras aulas, dentre outras opçōes, foi eleita em assembleia no momento das combinaçôes daquela aula. As regras que a integraram e regularam foram estabelecidas pelo mesmo processo que a elegeu, reelaboradas e dimensionadas por todos os protagonistas daquele processo, para o trato das necessidades e peculiaridades do coletivo. Entretanto, as regras, que se consubstanciavam nos princípios e normas gerais de convivência e que deveriam nortear as inter-relações e perdurar durante todo o interstício da pesquisa, foram preservadas.
O futebol foi a atividade que, de forma predominante, permeou o momento espontâneo da maioria dos meninos. Todavia, até aquele dia, não havia se apresentado como atividade coletiva. Nos momentos espontâneos ocorridos até então, os meninos apresentaram atitudes de discriminação e exclusão, em relação aos menos hábeis e, principalmente, no tocante à participação das meninas.

No processo de composição dos times, ocorreu, de modo gritante, a discriminação dirigida dos mais aos menos competentes. Perante tal situação, o professor interveio de maneira a resgatar os princípios que deveriam regular as atividades que viessem a ser desenvolvidas, ao longo da pesquisa, com destaque, nesse caso, para a regra $n^{\circ} 6$, que estabelecia que a discriminação de cor, de classe, de gênero, por afinidade ou competência, seria considerada como falta grave pelo grupo. As crianças "C1", "C3", "C4", "C7" e "C8" fizeram parte da composição do grupo "A" e "C2", "C5", "C6", "C9" e "C10", do grupo "B".

Durante o desenvolvimento dessa atividade, destacaram-se quatro ocorrências, que descrevemos a seguir:

1) "C3" fracassou sucessivas vezes, nas tentativas de executar passes a companheiros de time e finalizações ao gol adversário. "C7", criança extremamente hábil e agressiva, pertencente ao seu time, advertiu-o, dizendo: "ô, seu..., se errar mais uma vez, você vai ver só". Diante de tal cobrança, "C1" e "C2" se manifestaram solidários a "C3" e partiram, aos gritos e empurrões, em direção ao agressor;

2) "C8" interagia e atuava de maneira satisfatória no time " $A$ "; entretanto, ao sofrer a primeira cobrança de "C7", chorou e agrediu verbalmente o seu crítico, o que resultou em severas agressões físicas a ele, por parte de "C7". Diante da situação ocorrida, "C8", por se sentir inseguro, excluiu-se da atividade;

3) "C10" apresentou extrema inabilidade para com essa atividade; contudo, em nenhum momento tolerou atitudes mal sucedidas, advindas de seus companheiros. "C6", ao perder a posse de bola para um integrante do time oposto, foi agredido por "C10". Tentou revidar, porém, em razão de seu menor nível de força física, foi subjugado. Diante de tal ocorrência, "C9" se colocou em sua defesa, dizendo: "pode brincar sossegado, se alguém quiser bater em você, primeiro vai ter que bater em mim". Todavia, tal garantia não lhe foi suficiente para que continuasse a jogar. Em consequência, "C6" abandonou a atividade e não mais retornou a ela; 
4) "C4" e "C5", inclusas em times opostos, embora sendo meninas e atuando em uma atividade que, em geral, é de domínio dos meninos, mantiveram suas características de líderes. Quer dizer, estiveram à frente da organização tática de seu time. Destacamos, aqui, a postura de ambas em face das situaçôes de conflito ocorridas entre os dois times: houve uma ocasião em que não ficou claro, inclusive para o professor, se a bola, ao ter saído pela lateral da quadra, teria sido tocada por último por um integrante do time de uma ou de outra. Tal situação as levou a tomarem frente no embate em prol dos interesses de seus respectivos times. A situação instalada gerou um clima que se iniciou com um diálogo civilizado entre ambas e, aos poucos, evoluiu e rumou para agressões múltiplas, de sorte a contagiar a quase totalidade das crianças, de ambos os times. A princípio verbais, as agressōes passaram para o plano físico.

Em vista de cada uma das ocorrências citadas, o professor paralisou a atividade, solicitou que se retratassem, um em relação a outro e perante o grupo; em seguida, retomou e restabeleceu as regras e os combinados que deveriam reger a atividade. Tal processo consumiu o tempo destinado à atividade coletiva e invadiu parte do espaço temporal destinado ao momento espontâneo. Vale dizer que, em razão das ocorrências citadas, a atividade coletiva não foi concluída.

O resultado de tais atitudes culminou na privação do momento espontâneo para oito das 10 crianças. Nessa aula, as crianças que se beneficiaram do momento espontâneo foram "C8" e "C9". A aplicação de tal sanção se respaldou na consciência dos motivos para sua aplicação e majoritária concordância daquele coletivo.

\section{Etapa de intervenção 2}

Por fim, na etapa de intervenção 2, para que seja possível visualizar as implicações das atitudes individuais no contexto coletivo, tentaremos, ao descrever as ocorrências, fazer o contraponto desta para com as demais etapas que a antecederam. Para tanto, adotaremos, como eixo de nossa consideração, a observação e a análise comparativa do nível de desenvolvimento comportamental das crianças nas atividades representantes desta etapa, em relação às que se postam como amostragem, nas etapas anteriores.

Em razão de comportamentos positivos de grande parte do grupo, em aulas anteriores, decidimos que essa aula seria destinada, em sua integralidade, ao momento espontâneo. Assim, disponibilizamos às crianças os seguintes materiais: bola de futebol, bambolês e corda.

O objetivo, nessa aula, consubstanciou-se na observação e constatação do nível de independência das crianças, no que tange a suas capacidades em elaborar e gerir as atividades, de sorte a considerar os pressupostos que deveriam reger as inter-relações, naquele contexto. Diante de tal objetivo, a intervenção do professor somente se justificaria perante situaçôes de conflito que viessem a gerar agressões no plano físico.

As crianças se reuniram e, por meio da iniciativa de algumas delas, em especial de "C4" e "C5", a aula foi estruturada em dois momentos. No primeiro, a atividade desenvolvida seria o futebol e, no segundo, desafios individuais seriam compostos, através do objeto corda. Como opção das crianças, os bambolês não seriam empregados nas atividades estruturadas por elas.

Nas primeiras aulas do projeto, havia uma preocupação exacerbada dos mais competentes em se aglutinarem em um mesmo time; por sua vez, ao serem direcionados de forma frequente a times considerados fracos, a falta de motivação que contagiava os menos hábeis era a causa maior de suas frequentes desistências. No entanto, na atividade coletiva desse dia, os grupos foram constituídos de maneira equilibrada e sem maiores dificuldades.

Os alunos: "C4", "C5", "C9", "C6" e "C8" fizeram parte do grupo "A", enquanto "C1", "C2", “C2", "C7" e "C10", do grupo "B". Assim como durante as aulas em que o professor esteve à frente, houve, antes do início da atividade, um momento destinado aos grupos para reunir seus integrantes e combinar as estratégias e tarefas a serem compartilhadas, ao longo do jogo. Nos dois grupamentos, constatamos as seguintes falas: "primeiro, eu fico no gol e depois a gente troca, está bem assim?"; "eu fico na defesa, e você, onde quer ficar?"; "olha, o pessoal que está no ataque tem que ajudar a defesa também”, etc.

Nessa aula, como no exemplo empregado na etapa anterior, em suas tentativas de efetivar passes aos colegas de time e ao chutar ao gol adversário, "C3" falhou seguidas vezes, porém, nessa ocasião, em nenhum momento foi ameaçado ou agredido por companheiros de time ou mesmo por crianças que compunham o grupamento adversário. Ao fracassar, em uma de suas tentativas " "C7", criança pertencente a seu time, disse-lhe: "valeu, 'C3"'!; enfatizou ainda, de modo a auxiliá-lo, exemplificando: "olha, para que você possa acertar o chute, é necessário que toque a bola com a parte de dentro do pé, assim, ó". Por sua vez, "C1" complementou, dizendo: "não tem problema, na próxima você acerta". 
Outro ponto relevante a se ressaltar é o fato de que, de modo contrário ao comportamento exibido nas atividades desenvolvidas nas etapas anteriores, em suas atitudes, "C3", "C10", "C7" e "C9" colaboraram de forma satisfatória para com o desenvolvimento da aula. Em grande parte das situaçóes, esperaram e respeitaram os momentos adequados para ouvirem e serem ouvidos; cooperaram, através da consideração dos direitos de cada um e da necessidade da prevalência da vontade da maioria. Vale destacar que, ao findar do trabalho de campo, foram raros os momentos em que os flagramos tentando usurpar direitos alheios, o que muito auxiliou para a minimização de conflitos, naquela realidade. Todavia, "C9", por ser uma criança extremamente hábil e individualista, portou-se de maneira a não compartilhar atitudes de parceria para com os demais integrantes de seu time, com destaque para "C4" e "C5".

Por outro lado, "C6", que, nas etapas de intervenção 1 e 2 , se portou de modo apático, nesta fase se apresentou como o gestor da maioria das situações em que agressões físicas se manifestaram. Tais situaçôes se originaram das ações dessa criança para com as outras, durante os momentos em que o futebol se desenvolveu. Salientemos, como exemplo, a sua postura frente à situação de jogo, em que "C2" (criança pertencente ao time adversário) se encontrava com a posse de bola e rumava em direção ao gol de seu time. A atitude tomada pela criança em questão foi a de interceptá-lo, de forma a colocar em risco a sua integridade física. Tal atitude gerou turbulência e mal-estar. "C1", "C7" e "C10" partiram em defesa do companheiro de time, determinados a retribuir as atitudes de seu agressor. Em face dessa ocorrência, o professor se posicionou entre os dois lados, abrandou os ânimos e determinou que deveriam dar sequência à atividade.

Por sua vez, "C4" e "C5" continuaram a disputar a liderança no time "A". Ao se reunirem com as demais crianças, para efetivarem as combinaçōes necessárias, pudemos perceber a instalação de um clima de tensão. Ambas tentavam atrair a atenção dos demais integrantes, por meio de gritos e, algumas vezes, fazendo uso de palavras de baixo calão. No entanto, o ponto que mais se destacou foi a quase inexistência de atitudes consideradas como "faltas graves", ou seja, apesar de terem se exaltado e, em alguns momentos, serem impróprias as falas ali expressas, não se observaram agressões no plano físico. Ressalte-se que, das sugestôes apontadas por ambas, as proferidas por "C4" tiveram maior aceitação pelo grupo, o que se configurou como situação inédita, até aquele instante, com a aceitação, por parte de " $\mathrm{C} 5$ ", no que tangeu às decisões acolhidas pelo coletivo de seu time. Nesse clima e após a efetivação das combinaçôes coletivas nos grupamentos "A" e "B", a atividade transcorreu de maneira satisfatória.

Outro ponto a contrastar com o início do trabalho empírico é o fato de que, alémde concluir-se o jogo, verificou-se que o grupo "A" obteve êxito frente ao grupo " $\mathrm{B}$ ". Contudo, de forma contrária às anteriores, observou-se que o resultado foi aceito como uma possibilidade natural e provisória. Obtivemos tal conclusão, a partir das atitudes de parceria e companheirismo manifestadas imediatamente após a atividade, isto é, o time vencedor fez uma breve comemoração e, rapidamente, passou a interagir com o time vencido. O tema e a objetivação de tal comunicação tiveram como cerne a organização da segunda atividade, a ser desenvolvida naquele dia, ou seja, a organização dos desafios a serem transpostos através do objeto corda.

Essa segunda atividade, por se alicerçar em desafios individuais, as crianças decidiram que deveria se consubstanciar em regras do mesmo tipo das utilizadas no exemplo da etapa de intervenção 1 . No entender das crianças, para o pleno desenvolvimento da atividade, era necessária uma organização em coluna, de modo a se respeitar o direito de cada integrante a realizar três tentativas, bem sucedidas ou não. Assim, ao executar as tentativas, a criança deveria retornar ao final da coluna e aguardar, pacientemente, enquanto todas as outras, de igual maneira, fizessem uso de seus direitos, até que chegasse, de novo, a sua vez.

As tarefas elaboradas pela turma foram: com a corda a bater, as crianças deveriam passar zerinho uma por vez, ou seja, passar correndo de um lado a outro pelo centro da corda, procurando evitar que a mesma as tocasse; deveriam entrar, pular algumas vezes e, ao sinal, sair pelo mesmo lado pelo qual haviam entrado; deveriam entrar por um lado, pular algumas vezes e, ao sinal combinado, sair pelo lado oposto.

$\mathrm{Na}$ atividade em questão, percebeu-se que as crianças "C3", "C10", "C7" e "C9", diferentemente dos comportamentos socializados na etapa de intervenção 1 , colaboraram nos momentos das combinações e de desenvolvimento da atividade coletiva, de sorte a minimizar, de maneira significativa, a geração de conflitos. Verificaram-se, de igual modo, embora raras, algumas atitudes de solidariedade provindas de " $\mathrm{C} 1$ ", inclusive em relação a "C3”. Exemplo: "C3”, após fracassar em 
duas tentativas, quando do segundo desafio, que seria entrar na corda a bater, pulá-la algumas vezes e, ao sinal, sair pelo mesmo lado em que entrou, ouviu de "C1": "quando a corda estiver do outro lado, você entra e, quando ouvir o sinal para sair, saia logo depois que você a saltar". Por sua vez, "C6" e "C7" também avançaram nesse quesito, demonstrando atitudes de ajuda mútua, em algumas situações, para com algumas crianças, com destaque para "C8" e "C2", em relação ao primeiro, e "C10" e "C9", com respeito ao segundo.

Notou-se também, nessa aula, que "C8" evoluiu em seu processo de socialização, suportando pequenas críticas e apontamentos advindos de colegas de time, sem se frustrar e sem abandonar a atividade. Outro ponto relevante a mencionar foi o fato de que, ao atuar como goleiro, efetivou várias defesas, com sucesso. Isso foi imediatamente percebido e elogiado pelas demais crianças, de ambos os times.
Diante de situações como essa, "C8" teve sua autoestima promovida, o que o estimulou a interagir melhor com as crianças da turma em questão.

Apesar de "C4" e "C5" continuarem a apresentar atitudes de liderança, não observamos, nessa atividade, atitudes hostis de uma para com a outra, nem mesmo para com as demais crianças. Distintamente das ocorrências efetivadas na atividade representante da etapa de intervenção 1 , a maioria dos embates foi resolvida por meio do diálogo e, de ambas as partes, houve avanço na aceitação da vontade da maioria, quanto à organização e à estruturação das atividades.

Nota-se, pois, através da ilustração do processo de desenvolvimento das crianças por meio da análise das aulas descritas e do quadro em destaque, no tópico subsequente, que houve significativos avanços comportamentais, ao longo do desenvolvimento das diferentes fases desta pesquisa.

TABELA 1 - Desenvolvimento das crianças ao longo de três etapas da investigação.

\begin{tabular}{lccccccccc}
\hline \multirow{2}{*}{$\begin{array}{c}\text { Categorias } \\
\text { de análise }\end{array}$} & \multicolumn{3}{c}{ Etapa diagnóstica } & \multicolumn{3}{c}{ Etapa de intervenção 1 } & \multicolumn{3}{c}{ Etapa de intervenção 2 } \\
\cline { 2 - 10 } \multicolumn{1}{c}{ NS } & S & PS & NS & S & PS & NS & S & PS \\
\hline Respeito mútuo & $40 \%$ & $60 \%$ & $0 \%$ & $60 \%$ & $40 \%$ & $0 \%$ & $20 \%$ & $60 \%$ & $20 \%$ \\
Cooperação & $80 \%$ & $10 \%$ & $10 \%$ & $50 \%$ & $40 \%$ & $10 \%$ & $10 \%$ & $60 \%$ & $30 \%$ \\
Solidariedade & $60 \%$ & $20 \%$ & $20 \%$ & $30 \%$ & $40 \%$ & $30 \%$ & $10 \%$ & $30 \%$ & $60 \%$ \\
Perseverança & $80 \%$ & $0 \%$ & $20 \%$ & $50 \%$ & $30 \%$ & $20 \%$ & $10 \%$ & $30 \%$ & $40 \%$ \\
\hline
\end{tabular}

Fonte: Pesquisa de Mestrado - FCT/ UNESP, Campus de Presidente Prudente. Silvio Sena.

Resultado da análise do caderno de registros do trabalho empírico.
A TABELA 1 representa, em percentuais, os avanços de desenvolvimento, referentes às categorias de análise, obtidos pelas crianças ao longo deste trabalho.

Ao interpretar tal instrumento, notamos que, quanto à categoria respeito mútuo, na etapa diagnóstica, 40\% das crianças apresentaram seu nível de desenvolvimento enquadrado como NS, $60 \%$ como $S$ e $0 \%$ como PS. Na etapa de intervenção 1 , houve um acréscimo percentual das crianças que se encontravam como NS, isto é, de $40 \%$, na etapa diagnóstica, seu índice evoluiu para $60 \%$. Por sua vez, o índice de crianças PS, da etapa diagnóstica, se conservou, isto é, permaneceu em $0 \%$. Na etapa de intervenção 2 , houve uma migração do percentual de crianças que se encontravam como NS, para os níveis S e PS. Nesse trâmite, o desenvolvimento concernente às crianças, nesta categoria, mostrou-se, ao final da pesquisa, da seguinte forma: 20\% NS, 60\% S e 20\% PS.

$\mathrm{Na}$ categoria cooperação, na etapa diagnóstica, $80 \%$ das crianças tinham seu nível de desenvolvimento enquadrado como NS, 10\% como
S e $10 \%$ como PS. Na etapa de intervenção 1, houve um decréscimo percentual das crianças em NS, quer dizer, de $80 \%$, na etapa diagnóstica, reduziu-se para $50 \%$, enquanto o índice de crianças em PS, da etapa diagnóstica, se manteve em $10 \%$ e, o índice de crianças $S$ se elevou para $40 \%$. Na etapa de intervenção 2 , houve uma migração do percentual de crianças que se encontravam como NS para os níveis $S$ e PS. Nessa categoria, o desenvolvimento apresentou-se, ao final da pesquisa, da seguinte forma: $10 \%$ NS, $60 \%$ S e 30\% PS.

$\mathrm{Na}$ análise da categoria solidariedade, notamos que, na etapa diagnóstica, $60 \%$ das crianças foram enquadradas como NS, $20 \%$ como S e $20 \%$ como PS. Na etapa de intervenção 1 , houve um decréscimo percentual das crianças consideradas como NS, quer dizer, de 60\% na etapa diagnóstica, passou-se a 30\%, nessa etapa do trabalho; por sua vez, o índice de crianças S evoluiu para $40 \%$, enquanto PS, para $30 \%$. Na etapa de intervenção 2 , houve uma migração das crianças que se encontravam como NS, na etapa 1, para os níveis S e PS. Assim, na etapa de intervenção 2, a 
pesquisa apresentou $10 \%$ das crianças como NS, $50 \%$ S. e $40 \%$ como PS.

Por fim, ao considerar-se a categoria perseverança, tivemos, na etapa diagnóstica, $80 \%$ das crianças com nível de desenvolvimento enquadrado como NS, $0 \%$ como S e $20 \%$ como PS. Na etapa de intervenção 1 , houve um decréscimo percentual das crianças que se encontravam como NS, quer dizer, de $80 \%$ na etapa diagnóstica, verificaram-se $50 \%$, nessa etapa do trabalho. Por sua vez, o índice de crianças S evoluiu para 30\% e o percentual de crianças que se encontravam como PS manteve-se em $20 \%$. Na etapa de intervenção 2, houve uma migração de $40 \%$ das crianças que se encontravam como NS, na etapa 1, para os níveis S e PS. Assim, na etapa de intervenção 2, a pesquisa apresentou $10 \%$ das crianças como NS, 50\% como S e 40\% como PS.

Dessa maneira, ao findar da investigação, constatou-se que os avanços, destacados na TABELA 1 , transcenderam para outros ambientes. Como exemplo, citamos os relatos a seguir, proferidos pela maior parte dos professores regulares, ao elogiarem

\section{Conclusões}

A investigação, esteada no aprofundamento teórico, nas reflexões e nas experiências daqueles protagonistas, destaca algumas conclusōes que podem justificar o emprego do jogo como instrumento de intervenção, nas séries iniciais do Ensino Fundamental.

A primeira se refere à exigência de o professor ter conhecimento sobre como o jogo se configura e, a partir dele, favorecer o processo de socialização das crianças, no contexto escolar, uma vez que, segundo CAILloIs (1990), este não existe em si mesmo, mas se revela por meio de disposiçóes psicológicas do indivíduo, que o caracterizam.

Uma segunda conclusão, relevante para a efetivação do emprego do jogo como precursor de valores, concerne à necessidade de o professor apropriar-se de conhecimentos relativos às possibilidades de uso desse recurso, de sorte que este possa atuar positivamente na dimensão atitudinal e, também, como nas demais dimensões e aspectos da globalidade da criança. É preciso que o professor conheça diferentes tipos e a evolução dos jogos, e como se dá, com base nestes, a criação de novos jogos. A competência para estruturar um ambiente rico e propício ao jogo, no contexto educacional, exige do educador um profundo e abrangente conhecimento do tema e do desenvolvimento infantil. Ao dominar a prática e apontarem, em suas avaliações, os progressos feitos: "as crianças já não se agridem com a mesma frequência como ocorria no começo do processo, resolvem a maioria dos conflitos por meio do diálogo"; "ocorreram avanços em relação ao respeito das crianças às decisôes coletivas"; "as crianças aprenderam a ouvir e esperar, com paciência, seu momento de se pronunciar"; "eu percebo as crianças mais solidárias perante grande parte das dificuldades dos companheiros e das suas próprias"; "elas agora respeitam mais as regras instituídas pelo coletivo e não desistem com a mesma facilidade de antes, diante de dificuldades ou experiências de fracasso". Justificaram tais conclusões, afirmando que, em razão dos avanços supracitados, se tornou mais fácil ensinar. As crianças passaram a contribuir melhor para a instalação de um ambiente propício ao processo de ensino e de aprendizagem. Tais relatos foram socializados em Horários de Trabalho Pedagógico Coletivo (HTPCs) e Conselhos de Classe, Ciclo e Termo, ocorridos ao final do ano letivo.

educativa, o professor ouve, discute, propōe, ajusta, amplia e redimensiona o jogo, como uma situação lúdica precursora da socialização de conhecimentos, habilidades e valores.

Ao atender a essas exigências, o professor terá maior facilidade para estruturar e conduzir o ambiente lúdico ao encontro do nível de desenvolvimento proximal, no qual se encontra a criança. Tal zona de desenvolvimento "define aquelas funções que ainda não amadureceram, mas que estão em processo de maturação, funções que amadurecerão, mas que estão presentemente em estado embrionário" (VYGOTSKY, 1998, p.97).

Uma terceira conclusão indica que o emprego do jogo, no contexto educacional, pode ser enriquecido e potencializado pela qualidade e frequência das intervençôes do educador. Nesse prisma, constatamos que as crianças mais assíduas, ou seja, aquelas que sofreram um número maior de intervenções, foram as que mais avançaram, em todas as categorias de análise desta pesquisa.

Por último, o trabalho de campo possibilitou algumas outras conclusões. Como já enfatizado, os professores regulares afirmaram que os jogos repercutiram de maneira significativa, no comportamento das crianças, as quais ficaram mais motivadas, 
inclusive para frequentar a instituição, desenvolveram a autonomia, a confiança em si mesmas, mostrando-se mais curiosas, dispostas e perseverantes para outras aprendizagens. Dessa forma, evoluíram nas atitudes de cooperação, de respeito mútuo, de solidariedade e de troca de pontos de vista.

Avançar no emprego do jogo como conteúdo, recurso e meio globalizador, com vistas a uma formação plena da criança, significa, entre outros aspectos, o aprimoramento da competência docente. Quanto mais recursos o professor disponibilizar para a aprendizagem e para o desenvolvimento infantil, mais meios terá para alcançar os objetivos funcionais de sua disciplina e, de maneira simétrica, as finalidades educacionais. Tais posturas, comentadas aqui, podem atuar como promotoras de avanços qualitativos no atual sistema educacional, no Brasil.

Nessa perspectiva, a fundamentação teórica e o trabalho de campo realizado permitiram concluir, de forma semelhante a LIMA (2003), que a criança que mais joga é aquela que mais oportunidades têm de socializar e potencializar suas aprendizagens. Por outro lado, a criança que mais aprende também incorpora um conjunto de novas competências, as quais servem de suporte para o enriquecimento de seus jogos, além de outras múltiplas aprendizagens inerentes ao ser humano, com destaque, neste trabalho, para a formação de valores.

Portanto, ao fazer uso do jogo como recurso pedagógico, o educador deve organizar o ambiente educativo, a fim de instigar, motivar e conduzir esse recurso como uma atividade promotora de aprendizagens e, por consequência, de desenvolvimento.
Todavia, ao longo da pesquisa, nós nos deparamos com inúmeros obstáculos, destaque para: a dificuldade em organizar e sistematizar as atividades a partir da vontade e decisão da maior parte das crianças; a necessidade de o pesquisador atender a várias tarefas, como a realização simultânea da observação e da intervenção, durante o desenvolvimento das atividades; ainda, a efetivação dos registros, executada imediatamente após a cada aula; e a necessidade de, durante as fases da pesquisa, fazer valer as regras e combinados convencionados naquele coletivo, rumo à conquista das metas objetivadas, entre outras.

Apesar das dificuldades que, de certo modo, podem ter implicado nos resultados alcançados, concluímos que a pesquisa promoveu influências e repercussões positivas, no desenvolvimento das crianças. As conclusões enfatizadas podem servir de amparo para outras práticas educativas, tanto no que se refere à utilização do jogo como recurso pedagógico, na formação de valores, quanto à aquisição, por parte das crianças, das demais aprendizagens inerentes à Educação Física.

Enfim, as análises do trabalho empírico apontam e sublinham a importância e a pertinência do jogo, no contexto educacional. Tais conclusões reiteram o jogo como privilegiado conteúdo e instrumento de intervenção, para uma formação global das crianças, nas séries iniciais do Ensino Fundamental. Todavia, o jogo é uma atividade que, além de valores, reflete opções políticas e filosóficas, de sorte que compete ao educador atuar como mediador e enxergar o potencial de aprendizagem e de desenvolvimento que se esconde por trás das situações e atitudes lúdicas que o jogo promove.

\begin{abstract}
The game as a forerunner of social values in scholar context

This study has the objective of investigating the game as a forerunner of values in the school context. The aim of this analysis is the incorporation of values like cooperation, solidarity, mutual respect and perseverance by children. In order to do so, this study is based on the Historic-Cultural Theory and on authors who conceive education according to a globalized view. The qualitative methodology has characteristics of intervention, with qualitative and quantitative actions, in the following stages: diagnostic stage; intervention stage 1 ; and intervention stage 2 . In this process, knowledge produced was treated as a descriptive phenomenon. According to the results, there was a decrease in children's physical and verbal levels of aggression; they used the dialogue more frequently, as they needed to solve conflict situations originated in a playing-game context; there was a higher level of respect for the collective decisions; and reduced discrimination and exclusion attitudes. Based on the results of the research and the theoretical framework, this study leads to the conclusion that the game is a social
\end{abstract}


activity, thus, it is important to understand it as an essential component of playing culture enrichment; the Physical Education teacher must have a wide and deep comprehension about the game and children's development; finally, the usage of games in the educational context can be enriched by the quality and frequency of educator's interventions.

UnItERMs: Game; Values; Children; Socialization.

\section{Referências}

BRASIL. Secretaria da Educação Fundamental. Parâmetros Curriculares Nacionais: educação física. 3 ed. Brasil: MEC/ SEF, 2001.

CAILLOIS, R. Os jogos e os homens: a máscara e a vertigem. Lisboa: Cotovia, 1990.

ELKONIN, D.B. Psicologia do jogo. São Paulo: Martins Fontes, 1998.

GARÓFANO, V.V.; CAVEDA, J.L.C. O jogo no currículo da educação infantil. In: MURCIA, J.A.M. Aprendizagem através do jogo. Porto Alegre: Artmed, 2005.

LEONTIEV, A.N. Os princípios psicológicos da brincadeira pré-escolar. In: VIGOTSKY, L.S.; LURIA, A.R.; LEONTIEV, A.N. Linguagem, desenvolvimento e aprendizagem. São Paulo: Ícone/EDUSP, 1988.

LIMA, J.M. O jogar e o aprender no contexto educacional: uma falsa dicotomia. 2003. Tese (Doutorado em Educação)

- Faculdade de Filosofia e Ciências, Universidade Estadual Paulista, Marília, 2003.

MUKHINA, V. Psicologia da idade pré-escolar. São Paulo: Martins Fontes, 1995.

PONTECORVO, C. Discutindo se aprende: interação social, conhecimento e escola. Porto Alegre: Artmed, 2005.

PUIG, J.M. Práticas morais: uma abordagem sociocultural da educação moral. São Paulo: Moderna, 2004.

SANMARTÍN, M.G. Aprendizagem de valores sociais através do jogo. In: MURCIA, J. A. M. Aprendizagem através do jogo. Porto Alegre: Artmed, 2005.

VALENZUELA, A.V. O jogo no ensino fundamental. In: MURCIA, J.A.M. Aprendizagem através do jogo. Porto Alegre: Artmed, 2005.

VYGOTSKY, L.S. Pensamento e linguagem. São Paulo: Martins Fontes, 1989.

A formação social da mente: o desenvolvimento dos processos psicológicos superiores. São Paulo: Martins Fontes, 1991.

ZABALA, A. A prática educativa: como ensinar. Porto Alegre: Artmed, 1998.

Enfoque globalizador e pensamento complexo: uma proposta para o currículo escolar. Porto Alegre: Artmed, 2002.

\begin{tabular}{r|c} 
& \\
ENDEREÇO & \\
Silvio Sena & Recebido para publicação: 23/06/2008 \\
Av. Mathias Mendes Cardoso, 128 & Revisado: 29/09/2008 \\
e-mail:ssena1@itelefonica.com.br & Aceito: 20/07/2009 \\
19061-538 - Presidente Prudente - SP - BRASIL &
\end{tabular}

